\title{
Pengaruh Facebook Terhadap Keputusan Berkunjung Wisatawan Domestik Ke Pantai Pandawa, Bali
}

Ngurah Putu Nova Merta Pranitya a,1, Ida Bagus Suryawan a, 2

1'novamerta@outlook.com, 2idabagussuryawan@unud.ac.id

a Program Studi S1 Destinasi Pariwisata, Fakultas Pariwisata,Universitas Udayana, Jl. Dr. R. Goris, Denpasar, Bali 80232 Indonesia

\section{Abstract}

Pandawa Beach is one of beaches that located on the south coast of Bali Island, exactly in Kutuh Village, Kuta Selatan Subdistrict, Badung Regency. This beach is visited by hundreds of domestic tourists everyday. White sand, shallow beach, limestone hill, and also the clean torquoise water being photography or selfie objects in every single day by domestic tourists. The photos averagely uploaded to social medias everyday. This activity surely will affect many people to come and visit to Pandawa Beach. Thus, this case made the background of choosing the topic "Facebook's Effect toward Visiting Decision of Domestic Tourists to Pandawa Beach" to be researched. The goal of this research is to determine the significance of Facebook's effect toward visiting decision of domestic tourists to Pandawa Beach.

The research method that used in this research are quantitative research method with validity test analysis, reliability test, frequency test, t-test, and correlation analysis to analyze the Facebook's effect toward visiting decision to Pandawa Beach. Data sources are gained from primary data and secondary data. Data collecting technique used observation method, documentation, and using questionnaires. Sample of tourists determination technique used in this research is incidental sampling technique. This research is also limited with theory of planned behavior, concept of social media, concept of visiting decision, and concept of tourists.

The results of this research is that Facebook has effect toward the visiting decision of domestic tourists in Pandawa Beach but the effect is weak. This is caused that the tourist who visits Pandawa Beach also have references of another good beaches in online social media so the Pandawa Beach is not the location that prioritized or the only one tourist attraction that chosen to be visited by domestic tourists.

\section{Keywords: Facebook's Effect, Visiting Decision, Domestic Tourists, Pandawa Beach}

\section{PENDAHULUAN}

Indonesia sebagai negara kepulauan memiliki berbagai ragam keunikan alam dan budaya yang sudah terkenal hingga ke mancanegara. Keunikan alam dan budaya ini kerap dipromosikan baik oleh instansi resmi maupun oleh para wisatawan yang telah mengunjunginya. Media promosi yang sering digunakan yaitu media sosial melalui jaringan internet sehingga penyebaran informasi menjadi sangat cepat, murah, mudah, dan praktis.

Perkembangan teknologi informasi menjadi semakin pesat dan didukung oleh jaringan telekomunikasi yang semakin canggih, membuat dunia seakan tidak memiliki sekat ruang dan waktu. Media sosial sebagai salah satu media komunikasi masa kini telah menjadi konsumsi masyarakat Indonesia sehari-hari. Awalnya hanya sebagai media untuk melakukan percakapan tetapi kini sudah berkembang menjadi media berbagi foto maupun video. Media sosial yang digunakan bermacam-macam seperti Facebook, Twitter, Instagram, Path, Whatsapp, Line, dan lain-lain.
Bali sebagai salah satu destinasi wisata terkemuka baik di Indonesia maupun di dunia memiliki beragam daya tarik wisata yang tersebar dari hulu ke hilir. Ada banyak pantai yang menjadi daya tarik wisata baru dan penyebab cepat terkenalnya pantai-pantai tersebut adalah karena promosi melalui media sosial. Pantai Pandawa merupakan salah satu pantai di Bali yang terkenal akibat promosi melalui media sosial, salah satunya adalah media sosial Facebook.

Wisatawan yang datang ke Pantai Pandawa mayoritas merupakan wisatawan domestik. Pasir putih, pantai yang landai, bukit kapur, serta air laut yang bersih setiap harinya menjadi objek fotografi maupun selfie oleh para wisatawan domestik yang rata-rata diunggah ke media sosial bila berkunjung ke pantai ini. Dengan adanya unggahan foto dan video mengenai Pantai Pandawa di media sosial tentunya akan mengundang wisatawan lain yang belum pernah berkunjung ke Pantai Pandawa. Tidak heran mengapa begitu ramai wisatawan domestik memutuskan untuk berkunjung ke Pantai Pandawa yang mengakibatkan peningkatan jumlah kunjungan wisatawan domestik setiap tahunnya. 
Berdasarkan fenomena tersebut, penelitian ini dilakukan guna mengetahui pengaruh media sosial terhadap keputusan berkunjung wisatawan domestik ke Pantai Pandawa. Penelitian ini berfokus pada satu media sosial yakni media sosial Facebook. Tujuan dari penelitian ini adalah untuk mengetahui seberapa besar signifikansi pengaruh media sosial Facebook terhadap keputusan berkunjung wisatawan domestik ke Pantai Pandawa.

\section{TINJAUAN PUSTAKA}

Ada tiga telaah hasil penelitian sebelumnya yang berkaitan dengan penelitian ini. Telaah hasil penelitian sebelumnya yang pertama berkaitan dengan pengaruh media sosial yaitu penelitian yang dilakukan oleh Alique La Passawung (2014) dengan judul "Pengaruh Social Media Marketing terhadap Tingkat Kunjungan Coffee Toffee di Makassar". Telaah hasil penelitian sebelumnya yang kedua berkaitan dengan keputusan berkunjung yaitu penelitian yang dilakukan oleh Anjar Hari Kiswanto (2011) dengan judul "Pengaruh Harga, Lokasi dan Fasilitas terhadap Keputusan Berkunjung Wisatawan di Objek Wisata Dampo Awang Beach". Telaah hasil penelitian sebelumnya yang ketiga berkaitan dengan Pantai Pandawa yaitu penelitian yang dilakukan oleh Ayu Putu Wiweka Krisna Dewi dan Suprabadevi Ayumayasari Saraswati (2015) dengan judul "Kajian Pengembangan Usaha Budidaya Rumput Laut Di Pantai Kutuh, Badung, Provinsi Bali".

Adapun konsep yang digunakan dalam penelitian ini adalah konsep media sosial oleh Kotler (2012), konsep keputusan berkunjung oleh Kotler (2007), dan konsep wisatawan oleh Pitana (2009). Sedangkan teori yang digunakan adalah Teori Planned Behavior yang dikemukakan oleh Ajzen (2005).

Penelitian ini juga mengajukan hipotesis. Hipotesis merupakan jawaban sementara terhadap rumusan masalah penelitian. Adapun hipotesis yang diajukan dalam penelitian ini adalah sebagai berikut:

HO : Tidak ada pengaruh antara media sosial

Facebook terhadap keputusan berkunjung wisatawan domestik ke Pantai Pandawa.

H1 : Ada pengaruh antara media sosial Facebook terhadap keputusan berkunjung wisatawan domestik ke Pantai Pandawa.

\section{METODE PENELITIAN}

Data yang digunakan dalam penelitian ini bersumber dari data primer dan data sekunder. Data primer merupakan data yang diperoleh, diamati, dicatat, dan diindera secara langsung di Pantai Pandawa meliputi observasi kondisi Pantai Pandawa, penyebaran kuesioner pada wisatawan domestik, serta dokumentasi berupa foto-foto penelitian di Pantai Pandawa. Sedangkan data sekunder berupa data yang dikumpulkan dari berbagai jurnal serta data yang bersumber dari instansi kantor pengelola Pantai Pandawa seperti jumlah kunjungan wisatawan domestik, profil Pantai Pandawa, serta buku-buku, jurnal atau literatur lainnya.

Teknik pengumpulan data yang dilakukan dalam penelitian ini menggunakan observasi, dokumentasi, dan penyebaran kuesioner. Observasi dilakukan dengan tujuan untuk mendapatkan gambaran yang jelas mengenai situasi dan kondisi Pantai Pandawa. Dokumentasi dilakukan dengan cara mengumpulkan data-data dari dokumen yang diperoleh dari instansi kantor pengelola Pantai Pandawa seperti data jumlah kunjungan wisatawan domestik ke Pantai Pandawa serta artikel atau jurnal yang terkait dengan penelitian ini. Penyebaran kuesioner dilakukan untuk mendapatkan tanggapan wisatawan terhadap penggunaan media sosial Facebook dalam mengakses konten terkait Pantai Pandawa serta keputusan berkunjung wisatawan domestik ke Pantai Pandawa. Kuesioner diukur menggunakan Skala Likert dan disebarkan sejumlah 100 kuesioner yang respondennya merupakan wisatawan domestik.

Teknik analisis yang digunakan meliputi tiga tahap yaitu uji kuesioner, analisis statistik, dan uji hipotesis. Uji kuesioner meliputi uji validitas dan reliabilitas. Analisis statistik meliputi analisis frekuensi dan analisis korelasi sedangkan uji hipotesis dilakukan menggunakan uji t.

Uji validitas dan reliabilitas dilakukan dengan cara menyebarkan kuesioner kepada 30 orang responden sebagai sampel uji awal terlebih dahulu kemudian hasil kuesioner ditabulasikan dan diuji menggunakan alat uji SPSS. Kuesioner dikatakan valid jika variabel dalam kuesioner mempunyai nilai korelasi diatas 0,30 . Kuesioner juga dapat dikatakan 
reliabel bila nilai Cronbach Alpha lebih dari 0,60 .

Analisis data selanjutnya yang dilakukan adalah analisis frekuensi untuk mengetahui secara ringkas persentase pemilihan jawaban oleh responden pada masing-masing indikator pernyataan. Persentase jawaban akan menunjukkan tanggapan yang dominan dipilih berdasarkan skala Likert oleh responden.

Uji hipotesis merupakan analisis data selanjutnya yakni untuk menguji ada atau tidaknya pengaruh media sosial terhadap keputusan berkunjung wisatawan domestik ke Pantai Pandawa. Uji hipotesis dilakukan dengan cara uji t untuk mengetahui apakah variabel independen memiliki pengaruh terhadap variabel dependen secara individual dan menganggap dependen yang lain konstan. Ada atau tidaknya pengaruh tersebut dapat diketahui dengan cara membandingkan antara nilai t-tabel dengan nilai t-hitung. Apabila nilai t-hitung > t-tabel maka variabel independen memiliki pengaruh terhadap variabel dependen. Sebaliknya jika nilai t-hitung $<\mathrm{t}$ tabel maka variabel independen tidak memiliki pengaruh terhadap variabel dependen. Uji $t$ juga bisa dilihat pada tingkat signifikansinya. Jika tingkat signifikansi $<0,05$ maka variabel independen memiliki pengaruh terhadap variabel dependen. Namun jika tingkat signifikansi $>$ 0,05 maka variabel independen tidak memiliki pengaruh terhadap variabel dependen.

Analisis data yang terakhir adalah analisis korelasi untuk mengukur seberapa kuat hubungan antara variabel independen terhadap variabel dependen. Keeratan hubungan itu dinyatakan dengan nama signifikansi korelasi. Signifikansi korelasi dinilai dengan rentang nilai korelasi dari -1 sampai 1 . Apabila angka korelasi di atas 0,5 menunjukkan korelasi yang cukup kuat sedangkan di bawah 0,5 menunjukkan korelasi lemah. Selain itu signifikansi juga dinilai dengan tanda (negatif) dan + (positif). Bila hasilnya negatif menunjukkan bahwa arah hubungan berlawanan sedangkan hasil positif menunjukkan bahwa arah hubungan sama.

\section{HASIL DAN PEMBAHASAN}

1. Gambaran Umum Pantai Pandawa
Pantai Pandawa merupakan sebuah pantai yang terletak di Desa Kutuh, Kecamatan Kuta Selatan, Kabupaten Badung, Bali. Pantai ini berjarak sekitar $30 \mathrm{Km}$ dari pusat Kota Denpasar, tepat di bagian selatan kaki bukit Jimbaran. Pantai Pandawa ditetapkan sebagai kawasan wisata oleh Desa Kutuh pada tanggal 27 Desember 2012. Sedangkan pada tanggal 4 Agustus 2014, Bupati Badung menetapkan Pantai Pandawa sebagai Objek dan Daya Tarik Wisata dengan mengeluarkan Surat Keputusan Bupati Badung Nomor 43 Tahun 2014 tentang Penetapan Pantai Pandawa menjadi Obyek dan Daya Tarik Wisata (ODTW) Kabupaten Badung.

$$
\text { Pantai Pandawa (Pantai Kutuh) }
$$

sebelumnya dikenal dengan Secret Beach yakni sebutan para wisatawan asing terhadap pantai yang letaknya di bawah tebing dan tersembunyi. Pada dinding tebing sebelah utara jalan terdapat beberapa patung tokoh-tokoh Mahabharata seperti Dewi Kunti, Dharmawangsa (Yudhistira), Bima, Arjuna, Nakula, dan Sahadewa. Dengan adanya patungpatung ini membuat Pantai Kutuh disebutsebut sebagai Pantai Pandawa.

\section{Pengaruh Variabel Media Sosial Facebook terhadap Variabel Keputusan Berkunjung}

Pengaruh antara media sosial Facebook terhadap keputusan berkunjung wisatawan domestik ke Pantai Pandawa diketahui dengan melakukan beberapa analisis yakni uji validitas dan reliabilitas variabel Facebook dan variabel keputusan berkunjung, analisis frekuensi indikator pernyataan variabel Facebook, uji $t$ untuk membuktikan hipotesis, dan analisis korelasi variabel Facebook terhadap variabel keputusan berkunjung.

a. Uji Validitas Variabel Facebook dan Variabel Keputusan Berkunjung

Uji Validitas dilakukan untuk mengukur valid atau tidaknya pernyataan dalam kuesioner. Uji validitas yang dilakukan disini adalah uji validitas terhadap variabel Facebook dan variabel keputusan berkunjung. Dalam variabel Facebook terdapat 5 indikator pernyataan dan dalam variabel keputusan berkunjung terdapat 10 indikator pernyataan. 15 indikator pernyataan tersebut telah dijawab oleh 30 orang responden dan selanjutnya dikorelasikan dengan nilai total menggunakan analisis SPSS untuk mendapatkan hasil validitasnya. 
Validitas variabel Facebook diukur dengan melihat angka korelasi antara indikator (X1-X5) dengan nilai total variabel Facebook $(\Sigma$ $X)$. Sedangkan validitas variabel keputusan berkunjung diukur dengan melihat angka korelasi antara indikator (Y1-Y10) dengan nilai total variabel keputusan berkunjung ( $\Sigma$ Y). Apabila nilai berada di atas 0,30 maka indikator pernyataan adalah valid dan jika nilainya kurang dari 0,30 maka indikator pernyataan harus diganti.

Tabel 1 merupakan tabel uji validitas indikator pernyataan variabel Facebook (X) berdasarkan hasil alat hitung SPSS.

Tabel 1. Hasil Uji Validitas Indikator Pernyataan Variabel Facebook (X)

\begin{tabular}{c|c|c}
\hline Indikator & Nilai Korelasi & Keterangan \\
\hline X1 & 0,551 & Valid \\
X2 & 0,841 & Valid \\
X3 & 0,821 & Valid \\
X4 & 0,733 & Valid \\
X5 & 0,812 & Valid \\
\hline
\end{tabular}

Sumber : Hasil analisis data primer diolah dengan SPSS v.18 (2016) Pada tabel 1 seluruh indikator pernyataan (X1-X5) memiliki nilai koefisien korelasi positif dan lebih besar daripada 0,30. Maka dari itu, 5 buah indikator ini dinyatakan layak digunakan dalam penelitian.

Tabel 2 merupakan tabel uji validitas indikator pernyataan variabel keputusan berkunjung (Y) berdasarkan alat hitung SPSS.

Tabel 2. Hasil Uji Validitas Indikator Pernyataan Variabel Keputusan Berkunjung (Y)

\begin{tabular}{c|c|c}
\hline Indikator & Nilai Korelasi & Keterangan \\
\hline Y1 & 0,405 & Valid \\
Y2 & 0,461 & Valid \\
Y3 & 0,408 & Valid \\
Y4 & 0,594 & Valid \\
Y5 & 0,677 & Valid \\
Y6 & 0,522 & Valid \\
Y7 & 0,308 & Valid \\
Y8 & 0,789 & Valid \\
Y9 & 0,643 & Valid \\
Y10 & 0,802 & Valid \\
\hline \multicolumn{2}{|c|}{ Sumber : Hasil analisis data primer diolah dengan SPSS v.18 (2016) }
\end{tabular}

Pada tabel 2 seluruh indikator pernyataan (Y1-Y10) memiliki nilai koefisien korelasi positif dan lebih besar daripada 0,30. Maka dari itu, 10 buah indikator ini dinyatakan layak digunakan dalam penelitian.

b. Uji Reliabilitas Facebook dan Variabel Keputusan Berkunjung

Uji reliabilitas digunakan untuk mengukur konsistensi alat ukur penelitian yang dalam penelitian ini adalah kuesioner. Alat pengukur disebut reliabel bila alat ukur tersebut secara konsisten memberikan hasil atau jawaban yang sama terhadap gejala yang sama, walau digunakan berulang kali, yang berarti tetap stabil, dapat diandalkan, dan konsisten. Uji reliabilitas yang dilakukan disini adalah uji reliabilitas terhadap variabel Facebook dan variabel keputusan berkunjung. Dalam variabel Facebook terdapat 5 indikator pernyataan dan dalam variabel keputusan berkunjung terdapat 10 indikator pernyataan. 15 indikator pernyataan tersebut telah dijawab oleh 30 orang responden dan selanjutnya akan diuji menggunakan analisis SPSS untuk mendapatkan hasil reliabilitasnya.

Reliabilitas diukur dengan melihat angka Cronbach's Alpha. Apabila nilai berada di atas 0,60 maka indikator pernyataan adalah reliabel dan jika nilainya kurang dari 0,60 maka indikator pernyataan harus diganti.

Tabel 3 merupakan tabel uji reliabilitas variabel Facebook (X) dan variabel keputusan berkunjung (Y) berdasarkan hasil alat hitung SPSS.

Tabel 3. Hasil Uji Reliabilitas Variabel Facebook (X) dan Variabel Keputusan Berkunjung (Y)

\begin{tabular}{c|c|c}
\hline Variabel & $\begin{array}{c}\text { Cronbach's } \\
\text { Alpha }\end{array}$ & Keterangan \\
\hline Facebook (X) & 0,811 & Reliabel \\
Keputusan & 0,765 & Reliabel \\
Berkunjung (Y) &
\end{tabular}

Sumber : Hasil analisis data primer diolah dengan SPSS v.18 (2016) Pada tabel 3 dapat diketahui bahwa seluruh indikator pernyataan variabel Facebook (X1-X5) yang digunakan dalam penelitian ini adalah reliabel. Hal ini ditunjukkan dengan nilai Cronbach's Alpha sebesar 0,811 yang memiliki nilai positif dan lebih besar daripada 0,60. Maka dari itu, 5 buah indikator ini layak digunakan dalam penelitian.

Tabel 3 juga menunjukkan bahwa seluruh indikator pernyataan variabel keputusan berkunjung (Y1-Y10) yang digunakan dalam penelitian ini adalah reliabel. Hal ini ditunjukkan dengan nilai Cronbach's Alpha sebesar 0,765 yang memiliki nilai positif dan lebih besar daripada 0,60. Maka dari itu, 10 buah indikator ini layak digunakan dalam penelitian.

c. Analisis Frekuensi

Analisis frekuensi dilakukan untuk mengetahui secara ringkas persentase pemilihan jawaban oleh responden pada masing-masing indikator pernyataan. Persentase jawaban akan menunjukkan tanggapan yang dominan dipilih berdasarkan 
skala Likert oleh responden. Dengan analisis frekuensi ini akan diketahui tanggapan responden terhadap aktivitas terkait dengan penggunaan media sosial berdasarkan teori Planned Behavior dan keputusan berkunjung wisatawan tersebut menuju Pantai Pandawa.

Disini akan dilakukan analisis frekuensi pada indikator pernyataan variabel sosial media Facebook (X1) dan variabel keputusan berkunjung (Y). Indikator variabel Facebook yang dianalisis ada 5 indikator pernyataan sedangkan indikator variabel keputusan berkunjung yang dianalisis ada 10 indikator pernyataan. Analisis frekuensi akan menggambarkan jawaban yang dipilih oleh 100 orang responden berdasarkan skala Likert yakni Sangat Tidak Setuju, Tidak Setuju, Biasa Saja, Setuju, dan Sangat Setuju.

Tabel 4 merupakan hasil analisis frekuensi pada 5 indikator pernyataan variabel Facebook (X) berdasarkan hasil alat hitung SPSS

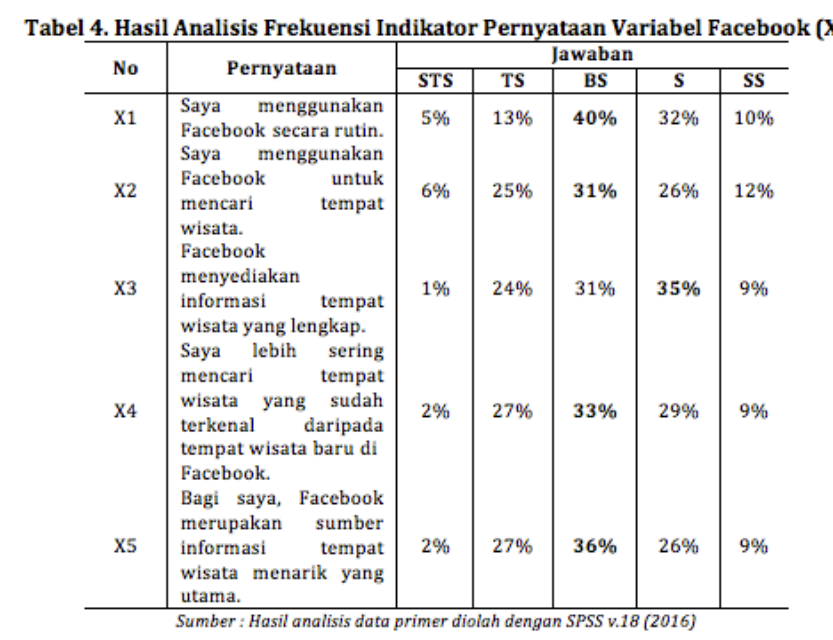

Tabel 4 menunjukkan bahwa 4 dari 5 indikator pernyataan variabel Facebook (X1, X2, X4, dan X5) didominasi oleh jawaban Biasa Saja sedangkan 1 dari 5 indikator pernyataan (X3) didominasi oleh jawaban Setuju. Pada tabel 5 ditunjukkan hasil analisis frekuensi pada 10 indikator pernyataan variabel keputusan berkunjung (Y) berdasarkan hasil alat hitung SPSS.
Tabel 5. Hasil Analisis Frekuensi Indikator Pernyataan Variabel Keputusan Berkunjung (Y)

\begin{tabular}{|c|c|c|c|c|c|c|}
\hline \multirow{2}{*}{ No } & \multirow{2}{*}{ Pernyataan } & \multicolumn{5}{|c|}{ Jawaban } \\
\hline & & STS & TS & BS & $S$ & SS \\
\hline Y1 & $\begin{array}{l}\text { Saya membutuhkan jasa pariwisata Pantai } \\
\text { Pandawa untuk berekreasi. }\end{array}$ & $0 \%$ & $8 \%$ & $34 \%$ & $51 \%$ & $7 \%$ \\
\hline Y2 & $\begin{array}{l}\text { Saya membutuhkan jasa pariwisata Pantai } \\
\text { Pandawa untuk mengisi waktu libur. }\end{array}$ & $1 \%$ & $10 \%$ & $26 \%$ & $\mathbf{5 2} \%$ & $11 \%$ \\
\hline Y3 & $\begin{array}{l}\text { Saya mengetahui Pantai Pandawa setelah } \\
\text { melihat media sosial Facebook. }\end{array}$ & $4 \%$ & $19 \%$ & $23 \%$ & $43 \%$ & $11 \%$ \\
\hline Y4 & $\begin{array}{l}\text { Saya memutuskan memilih berkunjung ke } \\
\text { Pantai Pandawa setelah mengetahui } \\
\text { keunikan yang tidak ada di pantai lainnya. }\end{array}$ & $2 \%$ & $2 \%$ & $20 \%$ & $49 \%$ & $27 \%$ \\
\hline Y5 & $\begin{array}{l}\text { Saya memutuskan memilih berkunjung ke } \\
\text { Pantai Pandawa karena Pantai Pandawa } \\
\text { memiliki fasilitas yang lebih lengkap } \\
\text { dibandingkan pantai yang lain. }\end{array}$ & $1 \%$ & $9 \%$ & $39 \%$ & $37 \%$ & $14 \%$ \\
\hline Y6 & $\begin{array}{l}\text { Saya memutuskan memilih berkunjung ke } \\
\text { Pantai Pandawa karena tidak ada } \\
\text { referensi pantai lain yang bagus di media } \\
\text { sosial online. }\end{array}$ & $4 \%$ & $39 \%$ & $31 \%$ & $22 \%$ & $4 \%$ \\
\hline Y7 & $\begin{array}{l}\text { Saya merasa yakin berkunjung ke Pantai } \\
\text { Pandawa sebagai pilihan yang tepat untuk } \\
\text { memenuhi kebutuhan saya dalam } \\
\text { berwisata. }\end{array}$ & $0 \%$ & $2 \%$ & $24 \%$ & $62 \%$ & $12 \%$ \\
\hline |Y8 & $\begin{array}{l}\text { Saya memilih berkunjung ke Pantai } \\
\text { Pandawa untuk meningkatkan gengsi dan } \\
\text { prestise. }\end{array}$ & $10 \%$ & $43 \%$ & $30 \%$ & $13 \%$ & $4 \%$ \\
\hline Y9 & $\begin{array}{l}\text { Saya merasa puas dan akan melakukan } \\
\text { kunjungan ulang ke Pantai Pandawa. }\end{array}$ & $2 \%$ & $0 \%$ & $15 \%$ & $62 \%$ & $21 \%$ \\
\hline Y10 & $\begin{array}{l}\text { Saya akan merekomendasikan Pantai } \\
\text { Pandawa kepada orang lain melalui media } \\
\text { sosial online yang saya miliki. }\end{array}$ & $1 \%$ & $0 \%$ & $13 \%$ & $46 \%$ & $40 \%$ \\
\hline
\end{tabular}

Pada tabel 5 ditunjukkan bahwa 2 dari 10 indikator pernyataan variabel keputusan berkunjung (Y6 dan Y8) didominasi oleh jawaban Tidak Setuju, 1 dari 5 indikator pernyataan (Y5) didominasi oleh jawaban Biasa Saja sedangkan 7 dari 10 indikator pernyataan (Y1, Y2, Y3, Y4, Y7, Y9, dan Y10) didominasi oleh jawaban Setuju.

\section{d. Uji Hiphotesis}

Penelitian ini menggunakan uji t untuk menguji hipotesis. Dengan uji $t$ ini akan diketahui ada atau tidaknya pengaruh variabel independen atau bebas (X) terhadap variabel dependen atau terikat (Y). Ada tidaknya pengaruh tersebut dapat diketahui dengan membandingkan antara nilai t-tabel dengan nilai t-hitung. Apabila nilai t-hitung $>$ t-tabel maka variabel independen $(X)$ memiliki pengaruh terhadap variabel dependen (Y). Sebaliknya jika nilai t-hitung < t-tabel maka variabel independen tidak memiliki pengaruh terhadap variabel dependen.Nilai $t$-tabel dihitung menggunakan rumus sebagai berikut:

t tabel $=\frac{a}{2}: n-k-1$

Dimana :

$a=$ taraf signifikansi

$n=$ jumlah responden

$k=$ jumlah variabel bebas

Nilai t-tabel dalam penelitian ini adalah

$$
\begin{aligned}
& \text { tabel }=\frac{0,05}{2}: 100-2-1 \\
& t \text { tabel }=0,025: 100-2-1 \\
& t \text { tabel }=0,025: 97
\end{aligned}
$$


Nilai t-tabel dapat dilihat pada tabel distribusi nilai t-tabel menggunakan acuan kolom taraf signifikansi 0,025 dan baris 97 sesuai perhitungan di atas. Dengan demikian, nilai t-tabel adalah 1,988.

Setelah dihitung menggunakan analisis regresi alat hitung SPSS, didapat nilai t-hitung Variabel Facebook adalah 3,741. Nilai tersebut lebih besar daripada nilai t-tabel yakni 1,988. Sedangkan nilai signifikansi variabel Facebook adalah 0,000 dan nilai tersebut lebih kecil 0,05. Dengan demikian, variabel Facebook (X) memiliki pengaruh terhadap variabel keputusan berkunjung (Y) sehingga $\mathrm{HO}$ ditolak dan $\mathrm{H} 1$ diterima.

e. Analisis Korelasi

Analisis korelasi merupakan tahapan analisis yang terakhir. Analisis korelasi dilakukan untuk mengukur seberapa kuat hubungan antara variabel independen terhadap variabel dependen. Analisis korelasi yang dilakukan disini adalah analisis korelasi antara variabel Facebook dan variabel keputusan berkunjung. Variabel Facebook berkedudukan sebagai variabel bebas (X) yang dapat memberikan pengaruh terhadap variabel keputusan berkunjung yang berkedudukan sebagai variabel terikat (Y).

Analisis korelasi yang dilakukan disini berdasarkan data kuesioner yang telah dijawab oleh 100 orang responden dan selanjutnya diuji menggunakan analisis SPSS untuk mendapatkan hasil korelasinya. Signifikansi korelasi dinilai dengan rentang nilai korelasi dari -1 sampai 1 . Apabila angka korelasi di atas 0,5 maka artinya korelasi cukup kuat sedangkan di bawah 0,5 menunjukkan korelasi lemah. Selain itu signifikansi juga dinilai dengan tanda - (negatif) dan + (positif). Bila hasilnya negatif menunjukkan bahwa arah hubungan berlawanan sedangkan hasil positif menunjukkan bahwa arah hubungan sama atau tidak berlawanan.

Setelah dihitung menggunakan analisis korelasi alat hitung SPSS, didapat nilai korelasi sebesar 0,377 . Dengan demikian dapat disimpulkan bahwa variabel media sosial Facebook positif memiliki pengaruh terhadap variabel keputusan berkunjung tetapi hubungannya lemah dikarenakan nilai korelasi 0,377 berada di bawah 0,5.

\section{SIMPULAN DAN SARAN}

Berdasarkan hasil penelitian dan pembahasan yang telah diuraikan maka diperoleh simpulan bahwa media sosial Facebook memiliki pengaruh terhadap keputusan berkunjung wisatawan domestik ke Pantai Pandawa. Berdasarkan analisis uji t, nilai t-hitung variabel Facebook (X) memiliki nilai sebesar 3,741 dan nilai ini lebih besar daripada nilai t-tabel yakni 1,988. Nilai signifikansi uji t variabel Facebook adalah 0,000 dan nilai ini lebih kecil dari 0,05. Sedangkan berdasarkan analisis korelasi variabel Facebook (X) terhadap variabel keputusan berkunjung memiliki nilai 0,377 dan nilai ini berada di bawah 0,5. Dengan demikian, variabel Facebook (X) memiliki pengaruh terhadap variabel keputusan berkunjung (Y) namun hubungannya lemah.

Saran yang dapat peneliti berikan kepada pihak pengelola Pantai Pandawa yakni agar melakukan promosi melalui media sosial Facebook dengan cara mengunggah kalender event yang akan diselenggarakan sewaktuwaktu di Pantai Pandawa. Ini akan lebih efektif dilakukan apabila dalam penyebaran informasi tersebut juga dibuktikan secara nyata di Pantai Pandawa sehingga wisatawan yang awalnya melihat informasi di media sosial kemudian memutuskan untuk berkunjung akan merasa bahwa ia diberikan informasi yang akurat dan tepat. Dengan adanya informasi yang lengkap akan meningkatkan kecenderungan wisatawan untuk berkunjung sekaligus berpotensi untuk membuat wisatawan menjadi repeater guest atau wisatawan yang datang berkunjung ke suatu tempat lebih dari sekali atau berkali-kali.

Saran juga diberikan kepada pihak Pemerintah Kabupaten Badung khususnya Dinas Pariwisata Kabupaten Badung agar memberikan dukungan dalam promosi daya tarik wisata Pantai Pandawa melalui media sosial Facebook agar masyarakat yang hendak berwisata ke Bali mendapatkan sebuah daya tarik wisata alternatif. Dengan demikian, media sosial dapat berperan secara aktif dan efektif untuk mendatangkan wisatawan baik domestik maupun mancanegara dan mampu mempengaruhi keputusan berkunjung wisatawan dari dalam dirinya sendiri. 
Daftar Pustaka:

Ajzen, I. (2005). Attitudes, personality, and behavior ( $2^{\text {nd }}$ ed.). Berkshire: Open University Press.

Anggraeni, Annisa Ayu. 2013. Analisis Dampak Ekonomi Wisata Bahari terhadap Pendapatan Masyarakat di Pulau Tidung. Jurnal Online Institut Teknologi Nasional, No.x, Vol.xx, Januari 2013.

Anonim. 2014. Peraturan Bupati Badung Nomor 43 Tahun 2014 tentang Penetapan Pantai Pandawa, Bali Elephant Camp dan Kawasan Jembatan Tukad Bangkung sebagai Daya Tarik Wisata di Kabupaten Badung.

2016. Rencana Kerja Anggaran Pendapatan dan Belanja Management Unit Usaha Pengelola Kawasan Wisata Pantai Pandawa - Kutuh (RKPB MP3-K) Tahun 2016.

2009. Undang-Undang RI No.10 Tahun 2009 tentang Kepariwisataan.

Dewi, Ayu Putu Wiweka Krisna dan Suprabadevi Ayumayasari Saraswati. 2015. Kajian Pengembangan Usaha Budidaya Rumput Laut di Pantai Kutuh, Badung, Provinsi Bali. Journal of Marine and Aquatic Sciences 2 (2016) 1-5.

Ghozali, I. 2011. Aplikasi Analisis Multivariate dengan Program IBM SPSS 19. Semarang : Badan Penerbit Universitas Diponegoro.

Kiswanto, Anjar Hari. 2011. Pengaruh Harga, Lokasi dan Fasilitas terhadap Keputusan Berkunjung Wisatawan di Objek Wisata Dampo Awang Beach Rembang. Skripsi. Jurusan Manajemen Fakultas Ekonomi Universitas Negeri Semarang.

Kotler, Phillip. 2007. Manajemen Pemasaran Jilid I (edisi $k e-12)$. Jakarta : PT Indeks.

Kotler, Philip. dan Keller, Kevin Lane. 2012. Marketing Management 14th ed. England : Pearson Education.

Kusmayadi dan Sugiarto, Endar. 2000. Metodologi Penelitian dalam Bidang Kepariwisataan. Jakarta : PT. Gramedia Pustaka Utama.

Passawung, Alique La. 2014. Pengaruh Social Media Marketing Terhadap Tingkat Kunjungan Coffee Toffee di Makassar. Skripsi. Jurusan Manajemen Fakultas Ekonomi dan Bisnis. Universitas Hasanuddin Makassar.

Pitana, I Gde dan I Ketut Surya Diarta. 2009. Pengantar Ilmu Pariwisata. Yogyakarta : ANDI.

Santoso, Singgih. 2014. Panduan Lengkap SPSS Versi 20 Edisi Revisi. Jakarta : PT Elex Media Komputindo.

Sevilla, Consuelo G. et. Al. 2007. Research Methods. Quezon City : Rex Printing Company.

Spillane, James P. 1994. Siasat Ekonomi dan Rekayasa Kebudayaan. Yogyakarta : Kanisius.

Sugiyono. 2011. Statistika untuk Penelitian. Bandung : Alfabeta.

Sugiyono. 2014. Metode Penelitian Kuantitatif, Kualitatif, dan R\&D. Bandung : Alfabeta.

Sumber lainnya :

maps.google.co.id (Diakses pada tanggal 6 Juni 2016 pukul 19:42)

people.umass.edu/aizen/tpb.html (Diakses pada tanggal 24 Mei 2016 pukul 15:57) 